\title{
DESIGN AND MANUFACTURE OF A WASTE COMPACTOR PROTOTYPE: A STEP TOWARDS IMPLEMENTING A NON-BURN HEALTH CARE WASTE DISPOSAL IN DEVELOPING COUNTRIES
}

\author{
Tito E. Mwinuka and Bavo B. Nyichomba \\ Department of Mechanical and Industrial Engineering, College of Engineering and \\ Technology, University of Dar es Salaam, P.O. Box 35131 Dar es Salaam, Tanzania \\ Email: tmwinuka@udsm.ac.tz, nyichomba@udsm.ac.tz
}

\begin{abstract}
Non-burn technology is the only safe way of handling and disposing infectious healthcare waste. It involves steam treatment of infectious waste at temperatures higher than $121^{\circ} \mathrm{C}$ for a minimum of 30 minutes before disposing them just like other municipal waste. Infectious healthcare waste is normally only about 10 $25 \%$ of all healthcare waste. In this paper, design, manufacturing and testing of a waste compactor for reducing waste volume to facilitate its handling is discussed. Preliminary tests show that the waste volume can be reduced to less than $10 \%$ of its original volume using the developed compactor. Waste compactors can serve urban hospitals where dumping space is a problem and the waste has to be transported. The compactor, developed by the University of Dar es Salaam team under the UNDP support, is capable of handling up to $25 \mathrm{~kg}$ of medical waste at a time and it is hydraulically operated. Furthermore, except for the hydraulic units and other electrical gadgets which can be bought as off-shelf parts, the designed waste compactor can be manufactured locally. The estimated total production cost was below USD 3,000. Part of UNDP requirements for this support was that the compactor design should be adopted by seven countries namely; Argentina, India, Latvia, Lebanon, Philippines, Senegal, Tanzania and Vietnam. These countries were nominated by UNDP to demonstrate the best techniques and practices of non-burn technologies in the developing countries.
\end{abstract}

Keywords: healthcare waste disposal, non-incineration waste disposal, waste compaction.

\section{INTRODUCTION}

\section{Background Information}

Health care activities produce significant volume of waste which needs to be disposed from time to time. This is due to the fact that if medical wastes are not disposed on time, they are likely to cause infections as well as becoming nuisance in terms of rodents and smell in hospitals. Medical wastes include things such as human organs; syringe sharps; bandages; cotton; gauze; plastic bottles; catheters and gloves. These can be classified into two main categories, namely; infectious and noninfectious waste.

In Tanzania, medical wastes in District, Regional, and some Referral Hospitals located in municipalities, are disposed by burning in open pits or using incinerators followed by burying of the ash in land pits around the hospitals. Off-site disposals are sometimes used when collection services are available. Incineration and open pit 
burning are associated with release of harmful gases like dioxins and furans. Emissions from incineration or open pit burning are known to be associated with the risk of cancer, birth defects, neurological defects, mental defects etc. (Thompson and Anthony, 2008). Due to this fact, developed countries are closing down their incinerators. There were over 2,300 incinerators in the US in 1996 but only less than 56 operate today (Cole and Mickey, 2011). As for some categories of pathological waste that cannot be incinerated, these are buried in placenta pits. However, for rural Health Centres where the space for disposal of waste is not a problem, sanitary landfills as well as the use of waste burning pits remain to be the cheapest options.

It is widely known that only $10-25 \%$ of the medical waste is infectious and hence a lot of research efforts have been directed on how to handle such wastes before their disposal (Stringer et al., 2009; SBC and WHO, 2004). Recently, there have been efforts to introduce waste management standardised segregation procedures of infectious medical waste in a number of hospitals in Tanzania by implementing a three bins systems that are systematically associated with colour coding and labelling. A red container collects infectious healthcare waste including body organs, bandages, cotton/gauze, catheters and gloves. A black container collects noninfectious waste (regular garbage). Yellow sharp boxes collect syringes and other sharps. All containers of healthcare waste should have the international biohazard label. In this case, infectious medical wastes can be autoclaved before dumping the same in landfills like any other municipal waste. Another method of handling of such waste is chemical treatment of the highly infectious waste. Although this kind of process is environmentally friendly as it does not generate dioxins, it is however unnecessarily expensive as it requires the use of expensive chemicals (Diaz et al.,
2005). However, it is important to note that as for chemical treatment of infectious medical wastes, some micro-organisms are more resistant than others. The most resistant micro-organisms to chemical treatment include bacterial spores and hydrophilic viruses (Diaz et al., 2005). Another alternative which is acceptable world wide and which is new to developing countries is the use of non-burn technologies.

Under the non-burn technology, hospitals face a challenge of compacting nonrecyclable waste before their disposal into the landfills especially in the urban areas where space for disposal of waste is a problem. Reduction of volume of the waste has an advantage of increasing the payload of the vehicle and reduces the number of times it has to empty.

Pursuant to the above, the Research and Development (R\&D) Team of the University of Dar es Salaam was nominated to demonstrate and promote the best techniques and practices for reducing health care waste to avoid environmental releases of dioxins and mercury. Such best practices are aimed at being shared by eight countries namely; Argentina, India, Latvia, Lebanon, Philippines, Senegal, Tanzania and Vietnam. The Tanzania component was mainly to undertake developing, testing and disseminating the technology for noncombustion disposal of medical waste to be replicated in above eight developing countries. The Project is funded by the Global Environmental Facility (GEF) through UNDP and working closely with WHO and Health Care Without Harm (HCWH).

This paper therefore concentrates on development of the waste compactor, its standardization, fabrication and documentation. It also covers prototype testing both in-house and extensive field tests with necessary refinements, test protocols and manuals. Lastly the paper 
covers efforts made in technology transfer and dissemination of the technologies developed to the public.

\section{METHODS AND MATERIALS}

To carry out the assignment as stipulated above, the following methodology was used:

(a) Review of Literature and Various Relevant Documents: This involved review of documents, available data and information relevant to the assignment.

(b) Field Studies: Field studies entailed meetings, consultations and interviews with various stakeholders both within and outside Tanzania. Since the concept of nonburn healthcare waste disposal was new to this country and other developing countries, members of the R\&D group at the College of Engineering (CoET) at the University of Dar es Salaam (UDSM) visited a number of industries in India dealing with waste disposals using non-burn technologies so as to get acquainted with the best technologies and practices that could be adopted by the Project members in their design, test and manufacture.

\section{(c) Design Concept and Embodiment}

Based on the analysis of findings from literature review as well as from field studies, it was possible to establish facts about design attributes that needed to be considered in order to come up with a suitable design of a waste compactor. The group established an evaluation matrix to evaluate different design concepts in terms of how best they conformed to preset specifications. The major attributes included in the design selection matrix were factors such as power source availability, capacity, materials, manufacturability, convenience of use, safety, cost and serviceability.

Sketches were prapared followed by full set of engineering drawings, that it, details drawings, design draft, sub assemblies and assembly drawing and were prepared using AutoCAD software. These drawings were used in the fabrication process.

\section{(d) Prototype Development and Testing}

Most development work involved fabrication using locally avilable raw materials like mild steel sheets, mild steel angle iron and round bars. Hydraulic and electrical systems parts that it hydraulic pump (including electric motor), pipes, double acting cylinder, directional control valves and electric motor control were later mounted onto the frame. Testing was done at the workshop using variety of waste including diapers, grass and papers. The test was also carried out at CCBRT hospital using real healthcare waste.

\section{OBSERVATIONS FROM PREVIOUS WORKS AND FIELD STUDIES}

The non-burn healthcare waste disposal technology involves waste segregation, autoclaving, shredding and volume reduction of waste so as to facilitate easy transportation of the same to land fills. The present review is summarised in three parts. Firstly, assessment of the volume waste generated on the daily basis in the Tanzania's hospitals. This was aimed at assisting in the selection of design variables that would be used in the designing of the compacting equipment including selection of waste containers for handling of medical waste in the non-burn technology. Secondly, previous survey of similar technologies on non-burn technologies as this assisted the team in the formulation of a number of alternative designs for the compactor. Thirdly, a survey of the locally available technologies in terms of local firm's manufacturing capacity and capability in mass production of waste compactors. The above information assisted the $R \& D$ group from CoET to design suitable compactor that could be manufactured locally. 


\section{Waste Disposal Needs for Hospitals in Tanzania}

As explained earlier, between $75 \%$ and $90 \%$ healthcare waste is non-risky or general healthcare waste, comparable to domestic waste (Stringer et al., 2010). Such medical wastes come mostly from the administrative and housekeeping functions of healthcare facilities and may also include waste generated during maintenance of health care premises. The remaining $10-25 \%$ of healthcare waste is regarded as hazardous (infectious) and may create a variety of health risks (Stringer et al., 2010). In nonburn technologies, handling and treatment of medical waste is therefore focused to infectious waste as this will cut unnecessary costs of handling non-infectious waste.

For the R\&D team to design the equipment for non-burn technologies with the right capacity to handle the generated medical waste in Tanzania and developing countries in general, it was important to know the amount of medical waste generated by these hospitals. In order to achieve the above, a non-governmental organization which is involved in healthcare research, AGENDA, undertook the task of identifying the volume of medical waste handled by district and regional hospitals as well as health centres and dispensaries in low-income African countries. For Tanzania's hospitals it was found that the estimated medical waste generated in referral, regional and district hospitals amounted to around 0.41 $\mathrm{kg}$ /occupied bed/day. For health centres and dispensaries, the waste generated amounted to around $0.03 \mathrm{~kg} /$ patient/day (AGENDA, 2009).

Also, data from the National Health Care Waste Management Plan report (URT, 2003), shows that the overall production of clinical waste in Tanzania is estimated between 12 and 14 tonnes per day. Out of the above amount, $50 \%$ of the health care waste is generated in the regions of Dar es Salaam, Kagera, Iringa, Kilimanjaro,
Arusha, Pwani and Mwanza due to large number of hospitals (referrals) and hence patients in these regions.

A survey by Manyele and Lyasenga (2010) conducted in low-level health facility in Dar es Salaam showed that waste segregation in most of the hospitals was not well practiced. Medical waste is handled or transported by hands or wheel barrows in plastic bags in big volumes to the point of disposal (e.g. to the incinerator). If this is done with autoclaved waste, transportation costs will raise due to increased number of trips required. It was also observed that incineration is still the most widely used method of medical waste disposal.

\section{Experience Gained from India for Non- Burn Technologies}

A survey by UDSM R\&D Team in India showed that there existed a number of industries that were capable of manufacturing of the following non-burn healthcare waste disposal equipment: autoclaves for sterilizing of healthcare wastes; plastic recycling machines; fibreglass reinforced articles that can be used to make waste containers; nonconventional and renewable equipment as well as machinery. In all cases, the team had a chance of having round discussions with the top management officials as well as visiting the workshops to see how different equipment and machinery were manufactured. A number of lessons were learnt. However, only those which were relevant to the subject are summarized here under.

\section{(a) Fibre glass Technology}

Fibre-glass reinforced plastics can be used to make several types of autoclavable containers for medical waste handling and treatment. As long as no direct heating is applied, fibre glass reinforced articles can be used at temperatures of around $140^{\circ} \mathrm{C}$ which is above the temperature required for 
non-burn technology of $121^{\circ} \mathrm{C}$. The products from this kind of technology are cheap since investment cost for manufacturing of the same is minimal. This is because the process does not require expensive machinery and moulds. Depending on mechanical strength requirement, various textures of and thicknesses of fibre glass can be selected. Colouring can be done during production by mixing resins with colours.

\section{(b) Shredding of Syringes}

Most plastic recycling machines are not specifically made for recycling syringes which also contain metallic parts i.e. needles and springs for retractable syringes. If these are used, the blades wear out quickly due to their contact with metallic components of syringes. Thus, in order to recycle syringes, the possible approach is first to cut the needle off the plastic part, using needle cutters, before the shredding of the plastic part. However, this approach adds a step which is risky to healthcare workers. Design and manufacture of needle cutters was dealt with by Mwinuka and Nyichomba $(2013,2014)$.

\section{(c) Sterilization of Hospital Wastes}

Agricultural wastes like rice husks, groundnut shells etc., which are plenty in rural areas, can be one of energy sources in sterilizing of hospital waste. What is needed is small bio-mass briquetting machine which can produce briquettes that can fire a steam generation unit. Gasification of these wastes may not be feasible for this application as it may turn to be unnecessarily expensive. Other sources of energy that could be used for sterilization of medical waste include the use of solar power especially in rural areas.

\section{(d) Training of Health Care Workers}

The use of waste treatment equipment will be more efficient if and only if proper training is conducted to all healthcare workers especially on waste segregation practice. In other words, what is needed is to implement "Total Waste Management" and not only "waste treatment and disposal". In India, incineration is still considered to be the most reliable way of treating hospital waste. However, the Indian Government has set environmental standards to be followed so that no harmful emissions are released. Some of the set standards include ensuring that no variations occur from the required conditions of $-30 \mathrm{~mm} \mathrm{Hg}, 1150^{\circ} \mathrm{C}$ and flue gases retention time of at least 1.5 seconds in post combustion chamber so as to prevent emission of harmful gases (McKay, 2002).

\section{(e) Autoclave Designs}

For a small health centre, vertical autoclave can be used. But also it is possible to have a horizontal autoclave with two doors, one for feeding of wastes in one room and the other for offloading of the waste containers. The two rooms (clean room and dirty room) can be separated by a wall. Again the source of heat, especially in rural areas, can be briquettes made from agricultural wastes thereby ensuring environmental preservation.

\section{Survey of Firms' Capability in Manufacturing the Non-Burn Technologies}

A number of local metal manufacturing firms were visited including SIDO workshops, TAZARA workshop, InterMech Workshop, Tanzim Enterprises Ltd. and $M \& R$ Enterprises. It was found that although most of the firms had basic manufacturing facilities for metal machining, arc welding, gas welding, flame cutting and metal forming, they were however not capable of manufacturing a number of non-burn technology equipment 
such as the autoclaves, waste compactors, medical waste containers and needle cutters under one roof. This is because no single firm had all the necessary equipment and machinery for manufacturing all of the nonburn equipment unless the above firms collaborate.

\section{Summary and Conclusion on Previous Works and Field Studies}

(i) Incineration is the most widely used disposal technology in developing world. Segregation of healthcare waste is still a major challenge in managing healthcare waste. (ii) Localised waste compaction equipment are not available in Tanzania's hospitals. (iii) Destruction of syringes after their use and compaction of other medical waste are necessary to implement a non-burn healthcare waste disposal technology. (iv) Shredders used for recycling of plastic can be used for destruction of syringes though they are likely to suffer short lifetime of the blades due to wear caused by the impact with metal parts of syringes.

\section{CONCEPTUAL DESIGN OF A COMPACTOR}

\section{Design Criteria for a Waste Compactor}

According to Technology Development Advisory Committee (TDAC) which is a special committee to oversee the designing and manufacturing of the first non-burn technology prototypes for developing countries like Tanzania, the prototypes developed need to abide to the following design criteria and conditions:

(a) Skills requirement: No specialized skills needed. A short training and demonstration should be able to make someone capable of operating the equipment. (b) Capacity: Should operate for at least a week for a medium sized hospital before need for emptying.

(c) Safety: Minimum risk of injuring the operator.

(d) Power source: electricity or manual.

(e) Manufacturability: Should be able to be manufactured in local workshops. No specialized processes needed.

(f) Production Cost: Less than USD 2,000 .

\section{Design Alternatives of the Waste Compactor}

\section{Concept 1: Horizontally Operated Manual Waste Compactor}

In this concept, a mechanically operated sliding plate is made to compress the collection of wastes from the hopper against a solid container (Figure 1). This system allows compaction of wastes as they are generated or in piece meals to a point where maximum weight of about $25 \mathrm{~kg}$ is attained. A baling system is incorporated through which the compacted waste can be bundled up before discharge (Figure 5).

\section{Concept 2: Horizontally Operated Hydraulic Waste Compactor}

This is structurally similar to the manual waste compactor except that the power screw is replaced by a double acting hydraulic cylinder and a hand operated 4 ports and 3 positions Directional Control Valve (4/3 DCV). In addition, it has an electrically operated hydraulic pump and hydraulic oil tank. A schematic diagram of this concept is shown in Figure 2.

\section{Concept 3: Vertical Compactor}

The mechanism for vertical compactor can be the same as horizontal compactors described above. However, a bevel gear system is needed for manual compactor so that the handles can still be rotated in vertical plane. The concept is shown in Figure 3 . The main disadvantage is the 
difficulty in achieving ergonomic waste loading height.

\section{Selected Best Concept}

Concept selection was done using evaluation matrix (Table 1) using criteria mentioned in Section 1.2(c). Although the mechanically operated compactor is simple to manufacture, it is limited in pressing force and compaction speed that can be achieved by a human effort. Given the fact that medical wastes are of numerous types composed of soft and hard items, it is important that the pressing force is high and consistent.

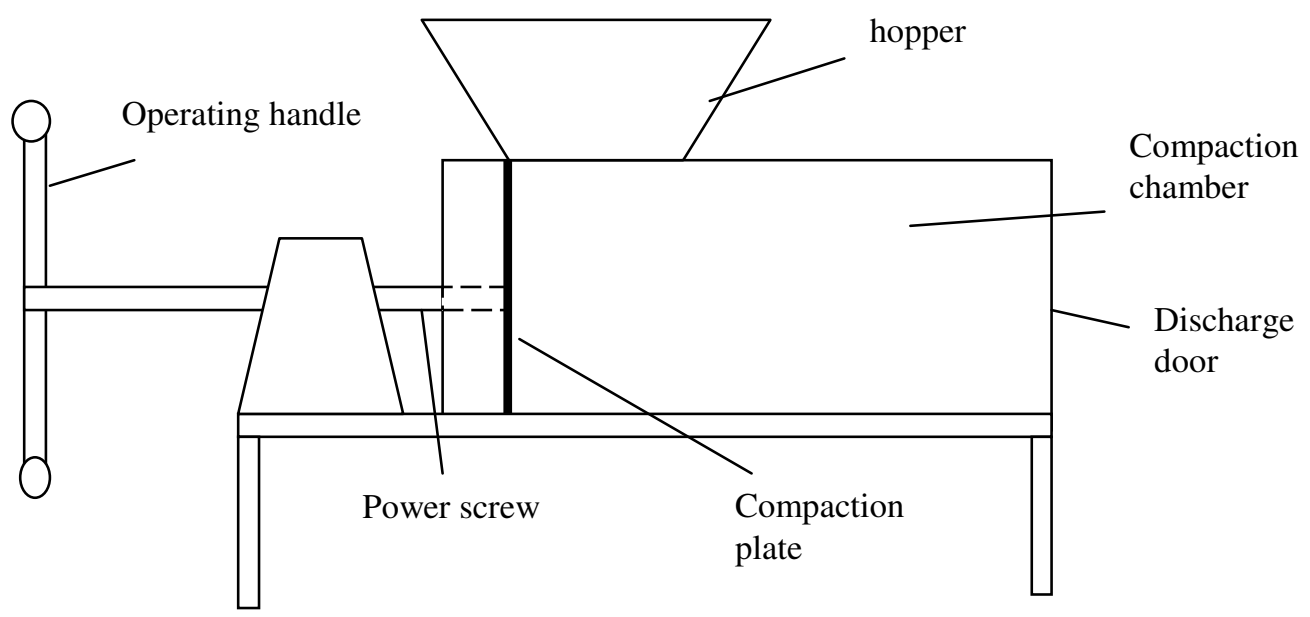

Figure 1: Schematic diagram of a manual waste compactor

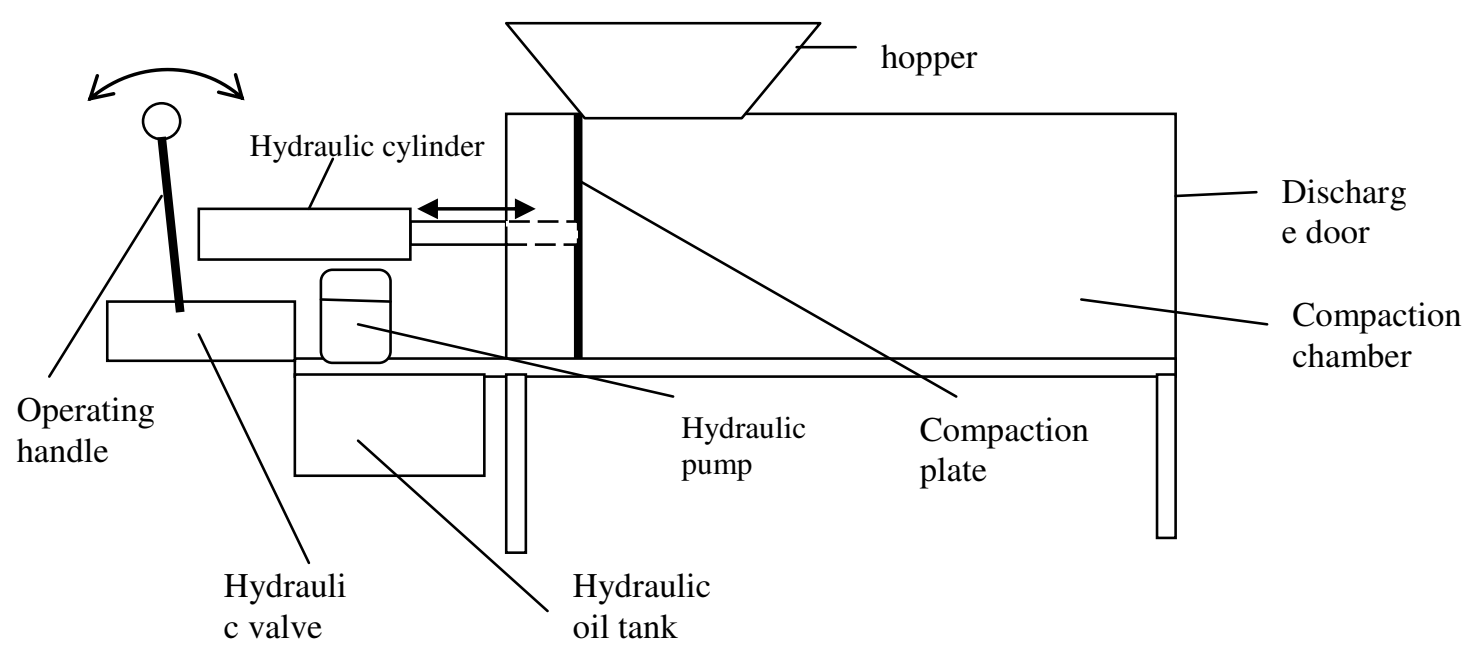

Figure 2: Schematic diagram of hydraulic waste compactor 


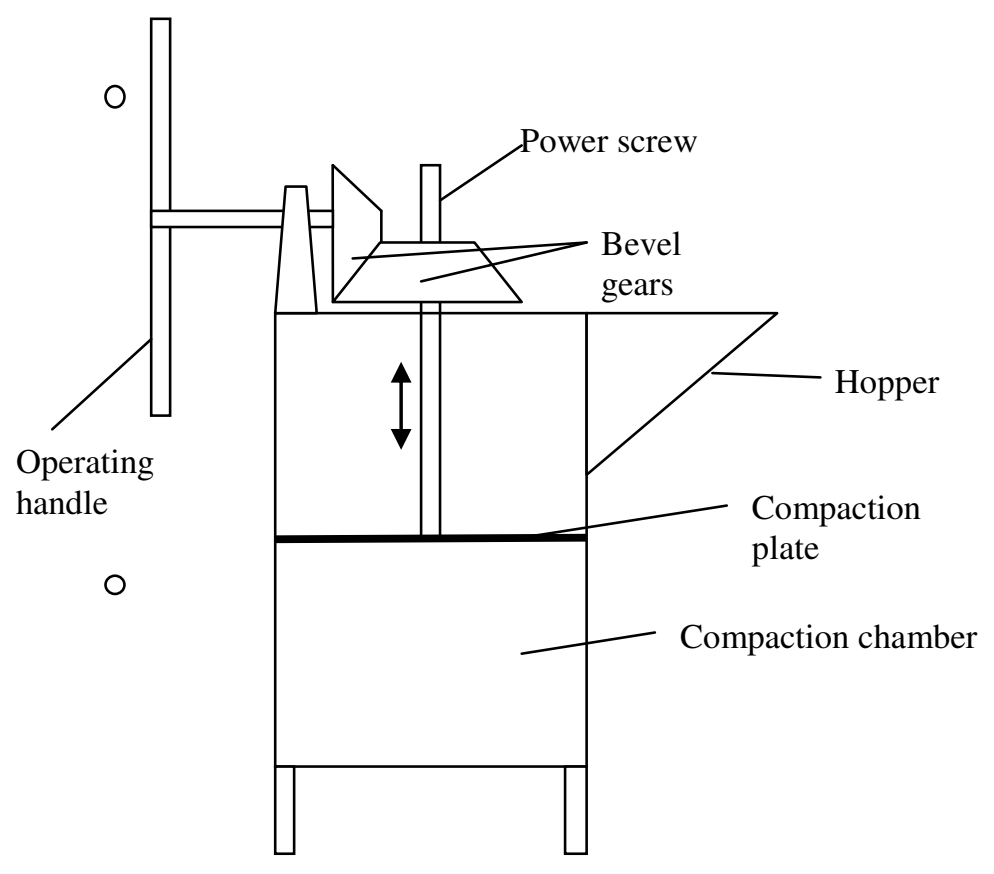

Figure 3: Schematic diagram of a vertical manual compactor

Table 1: Evaluation of Design Concepts

\begin{tabular}{|c|c|c|c|c|c|c|c|c|}
\hline \multirow[t]{2}{*}{$\mathrm{SN}$} & \multirow[t]{2}{*}{ Criteria } & \multirow{2}{*}{$\begin{array}{l}\text { Weight } \\
\text { W }\end{array}$} & \multicolumn{2}{|c|}{ Concept 1} & \multicolumn{2}{|c|}{ Concept 2} & \multicolumn{2}{|c|}{ Concept 3} \\
\hline & & & Score $\mathrm{S}$ & $\begin{array}{l}\text { Points } \\
\mathrm{S} * \mathrm{~W}\end{array}$ & ScoreS & $\begin{array}{l}\text { Points } \\
\mathrm{S} * \mathrm{~W}\end{array}$ & ScoreS & $\begin{array}{l}\text { Points } \\
\text { S*W }\end{array}$ \\
\hline 1 & $\begin{array}{ll}\begin{array}{l}\text { Power } \\
\text { availability }\end{array} & \text { source } \\
\end{array}$ & 0.1 & 7 & 0.7 & 5 & 0.5 & 7 & 0.7 \\
\hline 2 & Capacity & 0.2 & 4 & 0.8 & 8 & 1.6 & 5 & 1.0 \\
\hline 3 & Materials & 0.1 & 6 & 0.6 & 4 & 0.4 & 6 & 0.6 \\
\hline 4 & Manufacturability & 0.15 & 5 & 0.75 & 8 & 1.2 & 4 & 0.6 \\
\hline 5 & Convenience of use & 0.15 & 5 & 0.75 & 9 & 1.35 & 5 & 0.75 \\
\hline 6 & Safety & 0.1 & 6 & 0.6 & 5 & 0.5 & 6 & 0.6 \\
\hline 7 & Cost & 0.1 & 8 & 0.8 & 6 & 0.6 & 8 & 0.8 \\
\hline 8 & Serviceability & 0.1 & 7 & 0.7 & 6 & 0.6 & 7 & 0.7 \\
\hline & Total & 1 & & 5.7 & & 6.75 & & 5.75 \\
\hline
\end{tabular}


This can only be achieved by a manually or an electrically operated hydraulic press (Figure 2). For a manually operated hydraulic press it is envisaged that up to 5 $\mathrm{N} / \mathrm{mm}^{2}$ pressure will be attained whereas with an electrically operated hydraulic system, up to 150 bars or $15 \mathrm{~N} / \mathrm{mm}^{2}$ will be attained with electric motor of $1.5 \mathrm{~kW}$.

Manual waste compactor tests showed that much larger force need to be applied before a proper volume reduction is achieved. It was further observed that the force required to press a $25 \mathrm{~kg}$ waste to achieve a $90 \%$ reduction was beyond human capacity. Furthermore, the compressing speed was too low and hence time consuming.

Alternatively, the pressing force could be reduced by extending the turning moment handle. However, this is limited by the height of the equipment as well as the height of a human being. Furthermore, it was observed that there was a lot of waste spring back in this design due to low pressing force exerted manually.

In order to simplify the loading of waste to the compactor through the hopper, a horizontally operated press was recommended with height of loading being $1,120 \mathrm{~mm}$ from the ground. Off-loading of the compacted waste will be through the front end door of the compactor which is hinged at the top and is locked using a toggle mechanism so as to ensure fast opening and closing of the front door. There is also an off-loading table which is inclined so as to ensure the compacted waste slides smoothly to the ground.

\section{DESIGN FEATURES AND PROTOTYPE TESTING RESULTS}

A horizontal manually and electrically operated compactor prototypes was designed, manufactured (Figure 4) and tested. The results of testing are given below:

The selected design of the hydraulic waste compactor was found to be very robust in terms of compaction force and speed. In this case medical waste can be compacted to about $10 \%$ of original volume. A compression stroke takes about 5 seconds. However the compression process is progressive, that is every stroke adds compression to already previously compacted waste. On releasing the load, some spring back is observed nevertheless when left overnight under pressure, negligible spring back was observed after the release of the pressure. For medium sized hospitals, wastes can be compacted for several days before discharging the compacted waste.

Before off-loading of the compacted waste, baling of the same in two longitudinal directions should be carried out to reduce spring back or loosening of the waste during handling of the same as indicated in Figure 5. This design contains passages or grooves that allow the passing of ropes from different directions so as to tighten the waste while under pressure. A baling mechanism is incorporated in the front door of the compactor that facilitates the tightening of the waste thereby preventing it from falling apart. 


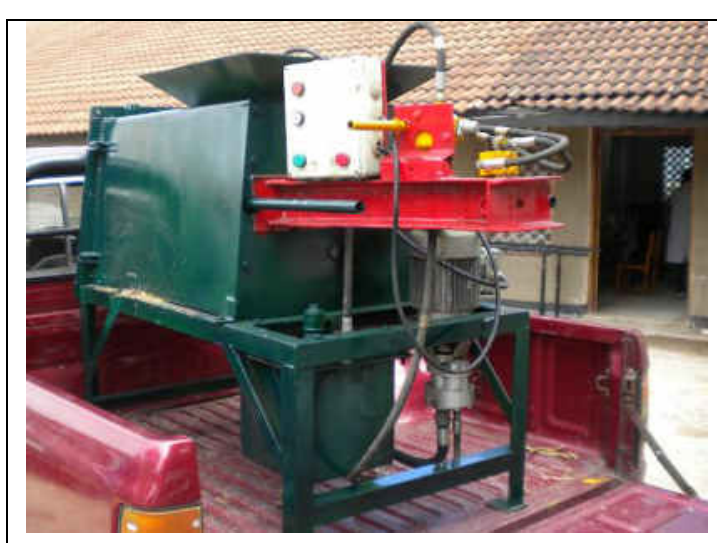

Fig. 4: A manufactured Compactor Prototype

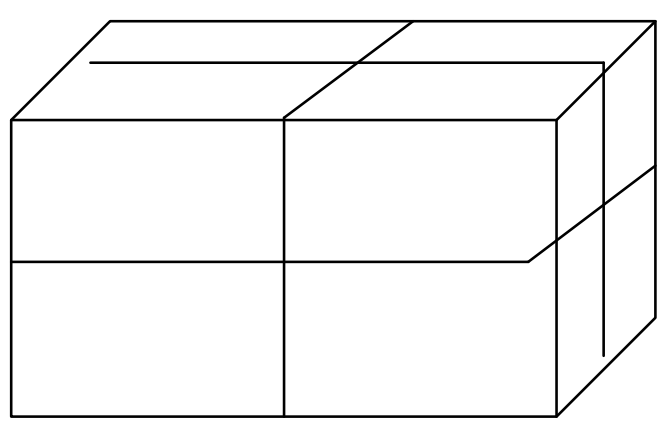

Fig. 5: Baling of the Waste

\section{CONCLUSIONS}

From what has been achieved so far in this project, it can be concluded that;

1. Waste compactors are important for successful implementation of non-burn hospital waste disposal technology.

2. There exist a number of workshops in the country that are capable of manufacturing about $90 \%$ of the components for the waste compactors leaving the remaining $10 \%$ of the components such as hydraulic system and pumps to be imported.

3. Inadequate expertise in designing and installation of hydraulic system could be a major bottleneck in the manufacturing of the hydraulically operated waste compactor.

4. Infectious medical waste must first be autoclaved and tested to be bacteria free before their compaction.

\section{REFERENCES}

AGENDA (2009). Needs Assessment for Hospitals in African Countries in Relation to Infectious Waste Treatment.

Cole C. and Mickey D. (2011). Medical waste in NC: the need to reduce incineration by more effective waste segregation and use of nonincineration technologies. A white paper submitted to NC Environmental Management Council.

Diaz L. F., Savage G.M. and Eggerth L.L. (2005). Alternatives for the treatment and disposal of Healthcare wastes in developing countries. Waste Management, 25: 626 637.

Manyele, S. V. and Lyasenga, T. J. (2010). Factors Affecting Medical Waste Management in Low-Level Health Facilities in Tanzania. African Journal of Environmental Science and Technology, 45(5): 304 318.

McKay G. (2002). Dioxin Characterization, formation and minimization during municipal solid waste (MSW) incineration: Review. Chemical Engineering Journal, 86: 343 368.

Mwinuka T. and Nyichomba B. (2013). Part 2: Handling of Syringes: A step Towards Implementing a Non-burn Health Care Waste Disposal Practice. pp. 52 58, Proceedings of the Third Annual International Conference on Innovation for Advancement of Humanity, 29th to 31st May 2013, Eldoret Polytechnic, Kenya.

Mwinuka T. and Nyichomba B. (2014). Handling of sharps in a nonincineration healthcare waste disposal. Unpublished paper 
submitted to the Tanzania Journal of Engineering and Technology.

SBC and WHO (2004). Preparation of National Health-Care Waste Management Plans in Sub-Saharan. Countries Guidance Manual.

Stringer R., Kiama J., Emmanuel J., Chenya E., Katima J. and Magoma F. (2010). Non-Incineration Medical Waste Treatment Pilot Project at Bagamoyo District Hospital, Tanzania.
Thompson J. and Anthony H. (2008). The Health Effects of Waste Incinerators. 4th Report of the British Society for Ecological Medicine.

United Republic of Tanzania (2003). National Health Care Waste Management Plan. 